\title{
Perioperative Results and Complications after Posterior Lumbar Interbody Fusion for Spinal Stenosis in Geriat- ric Patients over than 70 Years Old
}

\author{
Jong Min Choi, M.D., Man Kyu Choi, M.D., Sung Bum Kim, M.D., Ph.D. \\ Department of Neurosurgery, Kyung Hee University Hospital, Kyung Hee University School of Medicine, Seoul, Korea
}

Objective : As increasing the size of the geriatric population, the number of elderly patients, who need the surgery for painful degenerative spinal stenosis has been increasing. The geriatric population may be relatively high complications, because of age and age-associated medical conditions. However, there is a lack of studies addressing the perioperative complications and outcomes in elderly patients with posterior lumbar inter body fusion with screw augmentation (PLIF).

Methods : We retrospectively reviewed the medical records and radiographic studies of geriatric patients who had spine surgery of PLIF due to spinal stenosis for 11 years. We divided into 2 groups (A; 70-75 years, B; over then 76 years) according to the age. Surgical level of each groups, hospital day and postoperative day, co-morbidities, complications, clinical outcomes were analyzed. Operative reports, hospital and outpatient clinic charts, and radiographic studies were reviewed.

Results : Group A was composed of 80 patients, their mean age was 72.21 and female dominant $(n=46)$, and their mean surgically fused level was 1.52 level. Group B was 36 patients, their mean age was 78.83 and female dominant $(n=20)$, and their mean surgically fused level was 1.36 level. Comparing between two groups, complications, postoperative hospital stay were slightly increase in group B and co-morbidity was statistically high in group B, however clinical outcomes were similar between two groups.

Conclusion : Increasing age might be an important risk factor for complications in patients undergoing PLIF, however, we would like to recommend that if the situation of spine of extreme geriatric patients need PLIF, it should be in the surgeon's consideration after careful selection and clinical judgement.

Key Words : Lumbar vertebrae · Geriatrics.

\section{INTRODUCTION}

Aging is a natural process and is known for reduction in regeneration and repair of cells as time passes due to physical and mental alteration ${ }^{16}$. Degenerative spinal diseases from such aging are major anatomical structural changes and are mostly defined as diseases that compresses nerve roots due to stenosis in spinal canal or intervertebral neural foramen after degenerative changes in dynamic segment ${ }^{11,12)}$.

In these times when various changes like development of medicine and improvement in social environment lead to increased life expectancy, increased number of patients suffer

- Received : July 4, 2017 •Revised : July 18, 2017 •Accepted : August 16, 2017

- Address for reprints : Man Kyu Choi, M.D.

Department of Neurosurgery, Kyung Hee University Hospital, Kyung Hee University School of Medicine, 23 Kyungheedae-ro, Dongdaemun-gu, Seoul 02447, Korea Tel : +82-2-958-8114, Fax : +82-2-958-8113, E-mail : c55mc@naver.com

This is an Open Access article distributed under the terms of the Creative Commons Attribution Non-Commercial License (http://creativecommons.org/licenses/by-nc/4.0) which permits unrestricted non-commercial use, distribution, and reproduction in any medium, provided the original work is properly cited. 
from degenerative lumbar spondylosis ${ }^{7,16}$. Therefore, older patients require not only standard drug treatment and conservative treatment, but furthermore a treatment that reflects quality of life. However, when considering surgical treatment for patient diagnosed with spinal stenosis, important factor in deciding level of treatment is age.

Numerous studies have continuously reported higher rate of complications in older patients after surgical treatment ${ }^{8,12,14,23,28)}$. A study of patients aged 75 and older who underwent decompressive spine surgery reported a much higher complication rate (35.2\%), and it contains a major complication rate of $12.5 \%{ }^{8}$. Therefore, when we decide the therapeutic range of older patients who suffered from spinal stenosis, surgical treatment was hesitant due to relatively high complication rate ${ }^{13)}$.

However, in contrast, there have been numerous reports that older spinal stenosis patients have no difference in postsurgical complication or clinical outcome compared with younger patient $\mathrm{s}^{24,25,31,33,36)}$. Various techniques are globally being performed for surgical intervention on lumbar spinal stenosis and minimal invasive surgery, depressive surgery, and spinal fusion are universally practiced ${ }^{1722,34)}$. However, most of those studies are based on patients who have received decompressive surgery as subjects ${ }^{15,18,20,33,34)}$.

Therefore, the goal of this study lies in evaluating whether posterior lumbar interbody fusion with screw augmentation (PLIF) is appropriate for elderly patients aged over 75 after comparing clinical result and complications in different age groups of patients aged 70 or more.

\section{MATERIALS AND METHODS}

\section{Patient population}

This study is based on patients aged 70 or more who have received posterior lumbar fusion with pedicle screw fixation between January 2006 and December 2016 after being diagnosed with lumbar stenosis. Among 126 patients who have received fusion surgery, 116 patients, excluding $10 \mathrm{pa}-$ tients who met criteria for exclusion, have been divided into the group A with 80 patients aged from 70 to 75 and the group B with 36 patients aged more than 75 and evaluated for complication and outcome. For precise evaluation of spinal fusion outcome in degenerative spinal disease, pa- tients who have received fusion surgery from diseases other than degenerative spinal disease have been excluded. Exclusion criteria are as following : 1) patient who only have performed decompressive surgery; 2) patient diagnosed with spinal stenosis due to metastatic or spinal tumor; 3) Patient diagnosed with spinal stenosis due to trauma; and 4) infectious spinal disease.

\section{Radiologic evaluation}

Diagnosis of spinal stenosis was based on clinical symptoms, physical examination of neurology, simple lumbar spine $\mathrm{x}$-ray, lumbar magnetic resonance image, lumbar computerized tomography. All patients were conducted of conventional PLIF by single surgical team. After surgery, simple lumbar spine x-rays were obtained in 1 month, 3 months, 6 months, and 1 year. Successful spinal fusion was evaluated based on lumbar dynamic x-ray obtained 1 year after the surgery. Complete fusion was defined as 1) incorporation of grafts on both endplates; 2) presence of bridging trabecular bone across the interspace; 3) <2-degree movement on lateral flexion/extension views; and 4) absence of graft migration and subsidence ${ }^{2)}$.

\section{Pre-operative evaluation}

All patients were recorded of past medical history and comorbidities in medical record before surgery and preanesthetic evaluation was performed by our anesthesiologist. Anesthesia risk was evaluated based on American Society of Anesthesiologists (ASA) score. Clinical symptom of patients was estimated by Visual Analog Scale (VAS) score for back pain and lower extremity radicular pain.

\section{Post-operative evaluation}

Surgical level, hospital day, post-operative admission day, clinical symptom change, complication, postoperative outcome, radiologic and clinical evaluation were perfomed. Postoperative complications were further classified as major and minor complications following the literature which had been reported in 2008 by Cloyd et al. ${ }^{8}$. Major complication was defined as adversely affecting the recovery of the patient and minor complication was defined as recorded in the medical chart but did not alter the recovery of the patients. 


\section{Statistical method}

Statistical analysis in this study was conducted with SPSS for Windows (version 21.0; SPSS Inc., Chicago, IL, USA). Statistical significance was established with $p$ value of less than 0.05 .

\section{RESULTS}

\section{Patient population}

Average age was 72.71 in group A of 70-75 and 78.83 in group B over 75, with the oldest being 89 . Number of surgical treatment level was 1.52 for group A and 1.36 in group B, but it did not show statistical significance ( $p=0.142$, Table 1$)$.

\section{Pre-operative evaluation}

Number of co-morbidities in the patients was 125 in group A and 70 in group B. A group had average co-morbidities of 1.56 while B group had 1.94 and it has been evaluated that group B had more statistically significant co-morbidities ( $p=0.038$ ). In ASA score performed as pre-operative anesthetic evaluation, A group showed average of 2.23 (0-3), while older group showed 2.3 (1-4). With older age, pre-operative risk was higher, but it was not statistically significant $(p=0.258)$.

Table 1. Patient charateristics and preopertive result

\begin{tabular}{lccc}
\hline & Group A & Group B & $p$-value \\
\hline Mean age & $72.21(70-75)$ & $78.83(76-89)$ & 0.184 \\
Total patients & 80 & 36 & \\
Gender & & & \\
$\quad$ Male & $34(42.5)$ & $16(44.4)$ & 0.423 \\
Female & $46(57.5)$ & $20(55.6)$ & 0.315 \\
Surgical level & 1.52 & 1.36 & 0.142 \\
$\quad 1$ level & $41(51.2)$ & $24(66.6)$ & \\
2 level & $36(45)$ & $11(30.5)$ & \\
3 level & $3(3.8)$ & $1(2.9)$ & \\
Mean medical co- & $1.56(0-3)$ & $1.94(0-5)$ & $0.038^{*}$ \\
morbidity & $2.23(1-3)$ & $2.3(1-4)$ & 0.258 \\
\hline ASA scale &
\end{tabular}

Values are presented as number (\%) unless otherwise indicated. *Represents a statistically significant finding. ASA : American Society of Anesthesiologists
The most common co-morbidity was hypertension and patients might have diabetes, history of stroke, ischemic heart disease, chronic kidney disease, lung disease, and tumor or cancer (Table 2). Hypertension was most common in both groups and diabetes was more prevalent in older age group, with $32.5 \%$ in old group and $47.2 \%$ in older group.

As for VAS score on lower back pain and lower extremity radicular pain evaluated as pre-operative clinical symptom, group B showed higher score of lower back pain than group A, whereas pain from the radicular pain was higher in group A (Table 3).

\section{Post-operative evaluation}

\section{Post-operative complications}

In group A, 18 (22.5\%) post-operative complication occurred and 9 (25\%) complications occurred in 36 patients of group B. Post-operative complications were a slightly higher in group B, but there was no statistical difference between two groups. The most common complication was post-operative infection in both groups, and 2 cases of post-operative hematoma in surgical region occurred in group A. Also, there were major complications like pneumonia and stroke. In group B, 3 patients $(8.3 \%)$ occurred major complications and it is slightly higher rate than group A with 3 patients (3.75\%). However, there was no statistically significance. In addition, complications such as urinary tract infection, acute renal failure, leukopenia, post-operative delirium occurred (Table 4).

Table 2. Medical co-morbidity of patients

\begin{tabular}{cccc}
\hline & Group A & Group B & $\boldsymbol{p}$-value \\
\hline Hypertension & $54(67.5)$ & $29(80.5)$ & 0.132 \\
DM & $26(32.5)$ & $17(47.2)$ & $0.042^{*}$ \\
CVA & $7(8.7)$ & $3(8.3)$ & 0.45 \\
IHD & $4(5)$ & $6(16.6)$ & 0.074 \\
CRF & $4(5)$ & $3(8.3)$ & 0.371 \\
Lung disease & $4(5)$ & $4(11.1)$ & 0.222 \\
Cancer & $6(7.5)$ & $3(8.3)$ & 0.193 \\
\hline
\end{tabular}

Values are presented as number (\%). *Represents a statistically significant finding. DM : diabetes mellitus, CVA : cerebrovascular accident, IHD : ischemic heart disease, CRF : chronic renal failure 
Table 3. Postopertive result and hospital day

\begin{tabular}{|c|c|c|c|c|c|}
\hline & \multicolumn{2}{|c|}{ Group A } & \multicolumn{2}{|c|}{ Group B } & $p$-value \\
\hline Hospital day (days) & \multicolumn{2}{|c|}{$20.11(9-64)$} & \multicolumn{2}{|c|}{$21.63(10-71)$} & 0.243 \\
\hline Postoperative day (days) & \multicolumn{2}{|c|}{$17.6(8-56)$} & \multicolumn{2}{|c|}{$18.2(9-69)$} & 0.385 \\
\hline Complication & \multicolumn{2}{|c|}{$18(22.5 \%)$} & \multicolumn{2}{|c|}{$9(25 \%)$} & 0.387 \\
\hline \multirow[t]{2}{*}{ Non fusion rate } & \multicolumn{2}{|c|}{$8(10 \%)$} & \multicolumn{2}{|c|}{$4(11.1 \%)$} & 0.297 \\
\hline & Preopertive & Postoperative & Preopertive & Postoperative & $p$-value \\
\hline \multicolumn{6}{|l|}{ Clinical outcome } \\
\hline VAS (back) & 5.7 & 3.1 & 6.4 & 4.2 & 0.171 \\
\hline VAS (leg) & 6.3 & 2.5 & 6.2 & 2.4 & 0.297 \\
\hline
\end{tabular}

VAS : visual analog scale

Table 4. Postoperative complications for spinal stenosis patients with PLIF surgery

\begin{tabular}{lccc}
\hline & Group A & Group B & $\boldsymbol{p}$-value \\
\hline Postop infection & $5(6.25)$ & $3(8.3)$ & 0.452 \\
Postop hematoma & $2(2.5)$ & 0 & \\
Pneumonia & $2(2.5)$ & $2(5.6)$ & 0.332 \\
UTI & $3(3.75)$ & $2(5.6)$ & 0.276 \\
Delirium & $1(1.25)$ & 0 & \\
CVA & $1(1.25)$ & $1(2.7)$ & 0.462 \\
Neutropenia & $2(2.5)$ & 0 & \\
ARF & $2(2.5)$ & $1(2.7)$ & 0.381 \\
\hline
\end{tabular}

Values are presented as number (\%). PLIF : posterior lumbar inter body fusion with screw augmentation, UTI : urinary tract infection, CVA : cerebrovascular accident, ARF : acute renal failure

\section{Clinical \& radiographic outcomes}

In dynamic lumbar $\mathrm{x}$-ray performed 1 year after the surgery, $8(10 \%)$ in group A, and $4(11 \%)$ in group B was evaluated as failure in bone fusion. Average hospital day and post-operative day were higher in group B than group A, but it was not statistically significant. Both groups showed decrease in VAS score for lower back pain and lower limb radicular pain. Most patients showed high satisfaction after surgery.

\section{DISCUSSION}

With global increase in life expectancy, the number of elderly patients with painful degenerative spinal stenosis requiring surgery is expected to rise. Degenerative spinal disease is prevalent in geriatric population and age is an important fac- tor in deciding technique of surgery and its extent ${ }^{1,3,28,36)}$. Numerous studies have reported that post-operative complication is higher in old patients than younger patients ${ }^{9,12,16)}$. In a 2007 literature published by Daubs et al. ${ }^{12)}$, when patient aged 60 or more with spinal deformity received surgical treatment, $37 \%$ of the patients showed complication and percentage of serious complication such as pneumonia and stroke was $20 \%$. This is exceptionally high from $16.4 \%$ reported by a study of 2010 by Nasser et al. ${ }^{30)}$. that included 79417 patients who received surgery for degenerative spondylosis, which it is agreeable that age increases risk of post-operative complication. In our study, 25 patients of total 116 patients (21.5\%) underwent PLIF surgery showed post-operative complications, and 16 patients (20\%) were group A, 9 patients (25\%) were group B. It was similar results with complication rates of other literatures. In contrast, many studies report risk of post-operative complication in elderly patients is similar to that of young patients $^{27}$. In a large-scale retrospective cohort study with 2320 patients by Saleh et al. ${ }^{33}$ ), among old patients in age 80 or older who received lumbar spine surgery, $16.34 \%$ showed post-operative complication and 3.23\% showed serious complication. Such result is similar to the data of complication rates after spinal surgery that described Nasser et al. ${ }^{30}$, 2010 , which it makes surgical treatment to be a valid option for patients in old age. Also, Rihn et al. ${ }^{31)}, 105$ patients aged 80 or older who were diagnosed with spondylolisthesis and spinal stenosis and performed surgical treatment showed complication risk and mortality similar to young patient.

Furthermore, Cloyd et al." stated age alone is not determinant for avoiding surgery in patient with spinal disease. In other literature, low body weight (body mass index $<18.5$ ) was 
reported to be a crucial factor in predicting readmission of patient after surgery ${ }^{25,33)}$. Other than age and body weight, the fact that diabetes increases risk of complication after surgery is known from various literatures ${ }^{21,26)}$. Gruskay et al. ${ }^{23)}$ suggested bone fusion segment decides admission period and post-operative hospital day. In our study, there was no single important factor affecting the higher complication rates. Even co-morbidity was higher in group B than group A, but there was no significant difference in complication rates between two age group.

Outcome of surgical treatment in old-age patients with spinal disease is being reviewed positively in various papers. However, there are controversies on outcome and complication of minimal invasive surgery, decompression-only surgery, and intervertebral fusion ${ }^{4,6,14,29,32,37)}$. Epstein ${ }^{15)}$ reported surgeons prefer bone fusion in younger patients and when only decompressive surgery was performed, it showed similar improvement of symptoms as patient who received interbody fusion and the surgery can decrease complication of interbody fusion from hemorrhage during surgery and longer operation time. Furthermore, Dagistan et al. ${ }^{11)}$ insisted that 37 patients age from 65 to 86 who received minimal invasive decompressive surgery would be expected of significant improvement in quality of life.

However, there have been objective reports that PLIF is necessary for patients who progressed spinal instability after decompressive surgery ${ }^{5)}$. According to the paper by Glassman et al., lumbar interbody fusion can be considered as option for patients age 65 or older and post-operative complication does not influence clinical results ${ }^{22)}$. Coric and Branch $^{10)}$ reported that decompression-only surgery had failure risk of $30-40 \%$ in patients with symptomatic spinal stenosis and $10-20 \%$ of the patients came to have revision surgery. Also, they argued that instability may occur in patients who received decompression-only surgery, risk of lower back pain may be decreased, and post-operative complication is similar ${ }^{17,19,25,35)}$.

This retrospective study showed post-operative improvement of symptom and complication rate in elderly patient group aged over 75 who had similar surgery to patient group A in 70-75. Though group B showed significant increase in co-morbidities, but there was no significant difference in postoperative outcomes. Also, this study can be considered to have its significance in that it excludes patients who only had decompressive surgery and only selects old patients who have re- ceived PLIF as subjects. Degenerative change of spine is natural aging process and there were much more patients with spinal stenosis than only herniated intervertebral disc patients in elderly people. Even there is still controversial, concomitant fusion surgery after decompression has numerous benefits compared with only decompressive surgery especially, spondylolisthesis patients. Our study showed similar complication rates between group A and group B in spite of more medical co-morbities in group B. This results support performing PLIF surgery with elderly spinal stenosis patients. Therefore, it is suggested that surgeon will consider comparatively more invasive surgery in old patients aged 76 or older in deciding the extent of surgery.

However, this study has a disadvantage that it cannot be free of selection bias in a retrospective study and has limitation of comparatively irregular follow-up period and the fact that the outcomes are evaluated from only one surgical team.

\section{CONCLUSION}

Age is an important factor in deciding extent of surgical treatment in patients with spinal disease. Though there are controversies, it should be considered carefully as aging, itself, is risk of increasing post-operative complication risk. Many literature support higher post-operative complication risk of geriatric patients who undergone spinal surgery and it contains major complications such as stroke and pneumonia. However, as shown in the outcome of this study, older patients aged over 75 show significantly higher risk of comorbidities than patients in $70-75$, there is no statistically difference in post-operative complications and outcomes. It might be allowed various surgical treatment options to spinal stenosis patients who are refractory to conservative management. Also, comparatively invasive treatment like interbody fusion can be a valid option, depending on medical and physical status of individual patient.

\section{References}

1. Brown CH 4th, LaFlam A, Max L, Wyrobek J, Neufeld KJ, Kebaish KM : Delirium after spine surgery in older adults: incidence, risk factors, and outcomes. J Am Geriatr Soc 64 : 2101-2108, 2016

2. Burkus JK, Foley K, Haid RW, LeHuec JC : Surgical interbody research 
group--radiographic assessment of interbody fusion devices: Fusion criteria for anterior lumbar interbody surgery. Neurosurg Focus 10 : E11, 2001

3. Cassinelli E, Eubanks J, Vogt M, Furey C, Yoo J, Bohlman HH : Risk factors for the development of perioperative complications in elderly patients undergoing lumbar decompression and arthrodesis for spinal stenosis. SPINE (Phila Pa 1976) 32 : 230-235, 2006

4. Caputy A, Spence CA, Bejjani GK, Luessenhop AJ : The role of spinal fusion in surgery for lumbar spinal stenosis: a review. Neurosurg Focus $3:$ : 3, 1997

5. Caputy AJ, Luessenhop AJ : Long-term evaluation of decompressive surgery for degenerative lumbar stenosis. J Neurosurg 77 : 669-676, 1992

6. Cho KJ, Suk SI, Park SR, Kim JH, Kim SS, Choi WK, et al. : Complications in posterior fusion and instrumentation for degenerative lumbar scoliosis. SPINE (Phila Pa 1976) 32 : 2232-2237, 2007

7. Choma T, Rechtine GR, McGuire RA Jr, Brodke DS : Treating the aging spine. J Am Acad Orthop Surg 23 : e91-e100, 2015

8. Cloyd J, Acosta FL Jr, Ames CP : Complications and outcomes of lumbar spine surgery in elderly people: a review of the literature. J Am Geriatr Soc 56 : 1318-1327, 2008

9. Cloyd J, Acosta FL Jr, Cloyd C, Ames CP : Effects of age on perioperative complications of extensive multilevel thoracolumbar spinal fusion surgery. J Neurosurg Spine 12 : 402-408, 2010

10. Coric $\mathrm{D}$, Branch $\mathrm{CL}$ Jr : Posterior lumbar interbody fusion in the treatment of symptomatic spinal stenosis. Neurosurg Focus 3 : e5, 1997

11. Dagistan Y, Dagistan E, Gezici AR, Cancan SE, Bilgi M, Cakir U : Effects of minimally invasive decompression surgery on quality of life in older patients with spinal stenosis. Clin Neurol Neurosurg 139 : 86-90, 2015

12. Daubs M, Lenke LG, Cheh G, Stobbs G, Bridwell KH : Adult spinal deformity surgery: complications and outcomes in patients over age 60 . Spine (Phila Pa 1976) 32 : 2238-2244, 2007

13. Deyo RA, Cherkin DC, Loeser JD, Bigos SJ, Ciol MA : Morbidity and mortality in association with operations on the lumbar spine. The influence of age, diagnosis, and procedure. J Bone Joint Surg Am 74 : 536543, 1992

14. Dipierro CG, Helm GA, Shaffrey Cl, Chadduck JB, Henson SL, Malik JM : Treatment of lumbar spinal stenosis by extensive unilateral decompression and contralateral autologous bone fusion: operative technique and results. J Neurosurg 84 : 166-173, 1996

15. Epstein NE : Surgical management of lumbar stenosis: decompression and indications for fusion. Neurosurg Focus 3 : e1; discussion 1 p following e4, 1997

16. Fehlings M, Tetreault $L$, Nater A, Choma T, Harrop J, Mroz T, et al. : The aging of the global population: the changing epidemiology of disease and spinal disorders. Neurosurgery 77 Suppl 4 : S1-S5, 2015

17. Fox MW, Onofrio BM, Onofrio BM, Hanssen AD : Clinical outcomes and radiological instability following decompressive lumbar laminectomy for degenerative spinal stenosis: a comparison of patients undergoing concomitant arthrodesis versus decompression alone. J Neurosurg 85 : 793-
802, 1996

18. Fox MW, Onofrio BM : Indications for fusion following decompression for lumbar spinal stenosis. Neurosurg Focus 3 : e2; discussion 1 p following e4, 1997

19. Försth $P$, Michaëlsson $K$, Sandén B : Does fusion improve the outcome after decompressive surgery for lumbar spinal stenosis?: a two-year follow-up study involving 5390 patients. Bone Joint J 95 : 960-965, 2013

20. Galarza M, Fabrizi AP, Maina R, Gazzeri R, Martínez-Lage JF : Degenerative lumbar spinal stenosis with neurogenic intermittent claudication and treatment with the aperius perclid system: a preliminary report. Neurosurg Focus 28 : E3, 2010

21. Glassman SD, Alegre G, Carreon L, Dimar JR, Johnson JR : Perioperative complications of lumbar instrumentation and fusion in patients with diabetes mellitus. Spine J 3 : 496-501, 2003

22. Glassman SD, Carreon LY, Dimar JR, Campbell MJ, Puno RM, Johnson JR : Clinical outcomes in older patients after posterolateral lumbar fusion. Spine J 7 : 547-551, 2007

23. Gruskay JA, Fu M, Bohl DD, Webb ML, Grauer JN : Factors affecting length of stay after elective posterior lumbar spine surgery: a multivariate analysis. Spine J 15 : 1188-1195, 2015

24. Hudak EM, Perry MW : Outpatient minimally invasive spine surgery using endoscopy for the treatment of lumbar spinal stenosis among obese patients. J Orthop 12 : 156-159, 2015

25. Kilincer C, Steinmetz MP, Sohn MJ, Benzel EC, Bingaman W : Effects of age on the perioperative characteristics and short-term outcome of posterior lumbar fusion surgery. J Neurosurg: Spine 3 : 34-39, 2005

26. Lee JH, Chun HJ, Yi HJ, Bak KH, Ko Y, Lee YK : Perioperative risk factors related to lumbar spine fusion surgery in korean geriatric patients. J Korean Neurosurg Soc 51 : 350-358, 2012

27. Lee JY, Moon SH, Suh BK, Yang MH, Park MS : Outcome and complications in surgical treatment of lumbar stenosis or spondylolisthesis in geriatric patients. Yonsei Med J 56 : 1199-1205, 2015

28. Mahato NK, Sybert D, Law T, Clark B : Effects of spine loading in a patient with post-decompression lumbar disc herniation: observations using an open weight-bearing MRI. Eur Spine J 26 (Suppl 1) : 17-23, 2017

29. Marbacher S, Mannion AF, Burkhardt JK, Schär RT, Porchet F, Kleinstück $F$, et al. : Patient-rated outcomes of lumbar fusion in patients with degenerative disease of the lumbar spine. Spine (Phila Pa 1976) 41 : 893-900, 2016

30. Nasser R, Yadla S, Maltenfort MG, Harrop JS, Anderson DG, Vaccaro $A R$, et al. : Complications in spine surgery. J Neurosurg Spine 13 : 144-157, 2010

31. Rihn JA, Hilibrand AS, Zhao W, Lurie JD, Vaccaro AR, Albert TJ, et al. : Effectiveness of surgery for lumbar stenosis and degenerative spondyIolisthesis in the octogenarian population. J Bone Joint Surg Am 97 177-185, 2015

32. Rouben $\mathrm{D}$, Casnellie $\mathrm{M}$, Ferguson $\mathrm{M}$ : Long-term durability of minimal invasive posterior transforaminal lumbar interbody fusion. J Spinal Disord Tech 24 : 288-296, 2011 
33. Saleh A, Thirukumaran C, Mesfin A, Molinari RW : Complications and readmission after lumbar spine surgery in elderly patients: an analysis of 2,320 patients. Spine J 17 : 1106-1112, 2017

34. Thomé $C$, Zevgaridis $D$, Leheta $O$, Bäzner $H$, Pöckler-Schöniger $C$, Wöhrle J, et al. : Outcome after less-invasive decompression of lumbar spinal stenosis: a randomized comparison of unilateral laminotomy, bilateral laminotomy, and laminectomy. J Neurosurg Spine 3 : 129-141, 2005

35. Tuite GF, Stem JD, Doran SE, Papadopoulos SM, McGillicuddy JE, Oyedijo DI, et al. : Outcome after laminectomy for lumbar spinal stenosis. Part I: clinical correlations. J Neurosurg 81 : 699-706, 1994

36. Vitaz TW, Raque GH, Shields CB, Glassman SD : Surgical treatment of lumbar spinal stenosis in patients older than 75 years of age. J Neurosurg 91(2 Suppl) : 181-185, 1999

37. Weinstein JN, Lurie JD, Tosteson TD, Zhao W, Blood EA, Tosteson AN, et al. : Surgical compared with nonoperative treatment for lumbar degenerative spondylolisthesis. Four-year results in the spine patient outcomes research trial (SPORT) randomized and observational cohorts. J Bone Joint Surg Am 91 : 1295-1304, 2009 